ISSN 2236-0859

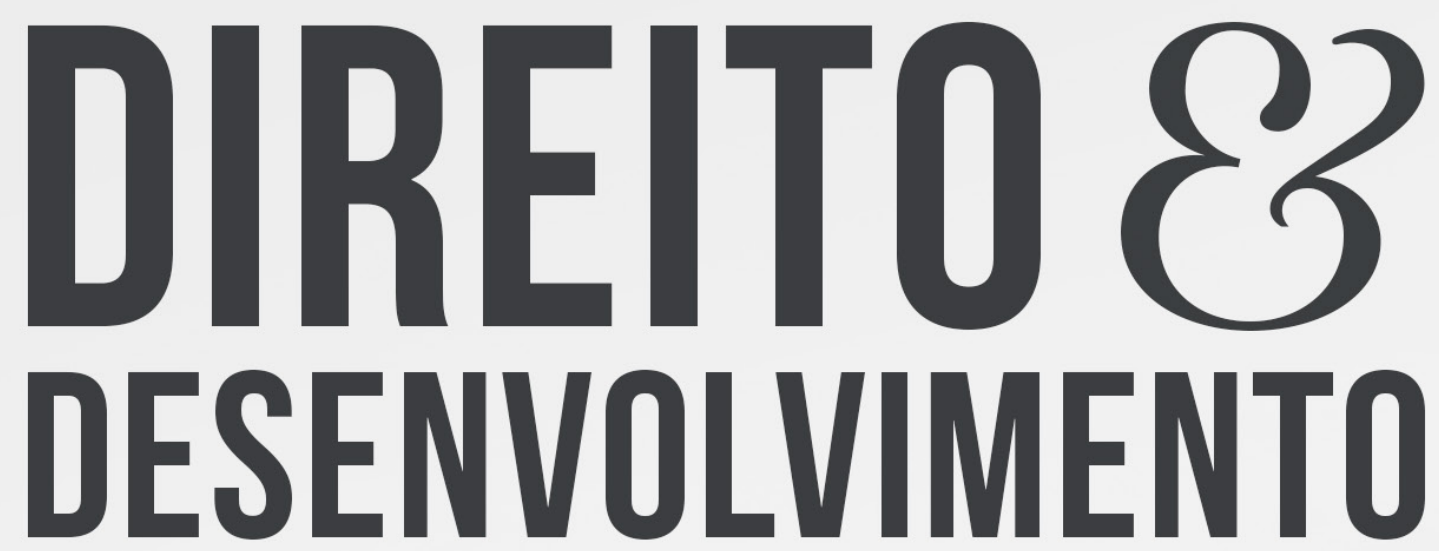

REVISTA DO PROGRAMA DE PÓS-GRADUAÇÃO EM DIREITO MESTRADO EM DIREITO E DESENVOLVIMENTO SUSTENTÁVEL

SUPERENDIVIDAMENTO E ACESSO À JUSTIÇA:

EXPECTATIVAS SOBRE A AUTOCOMPOSIÇÃO PARA O TRATAMENTO DOS CONFLITOS DECORRENTES DAS RELACOÕES DE CONSUMO

KARINNE GOETTEMS DOS SANTOS

ANA CARLA DE OLIVEIRA BRINGUENTE 


\title{
SUPERENDIVIDAMENTO E ACESSO À JUSTIÇA: EXPECTATIVAS SOBRE A AUTOCOMPOSIÇÃO PARA O TRATAMENTO DOS CONFLITOS DECORRENTES DAS RELAÇÕES DE CONSUMO
}

\section{OVER-INDEBTEDNESS AND ACCESS TO JUSTICE: EXPECTATIONS ON AUTOCOMPOSITION FOR TREATMENT OF CONFLICTS IN CONSUMER RELATIONS}

Recebido: 31/07/2018

Aprovado: 17/06/2019
Karinne Goettems dos Santos ${ }^{1}$ Ana Carla de Oliveira Bringuente ${ }^{2}$

\section{RESUMO:}

Na sociedade contemporânea, o consumo e seus excessos têm afetado a qualidade de vida do cidadão, tamanhaaintervençãodaeconomia nasrelaçõessociaisepessoais. Osuperendividamento é o resultado dessa interferência e a causa de tantos outros conflitos enfrentados pelo cidadão. No âmbito desta temática, este trabalho propõe-se a avaliar o ambiente adversarial disciplinado pelo novo CPC para tratamento das demandas repetitivas, aplicável às relações de consumo repetitivas. Num segundo momento, o trabalho procura destacar a autocomposição como espaço adequado para tratamento dos conflitos suportados pelo consumidor superendividado. Neste aspecto, o artigo destaca o Projeto de Tratamento do Superendividamento, capitaneado TJRS desde 2006, bem como o Projeto de Lei no 3515/2015, que tramita na Câmara dos Deputados, ambos voltados à promoção de políticas públicas, de caráter multidisciplinar, que destacam a reeducação do consumidor e a conciliação como ferramentas de superação do quadro de superendividamento. Para tanto, o artigo vale-se do método hipotético-dedutivo e espera alcançar, como possíveis resultados de análise, a demonstração de que, para situações complexas vividas pela sociedade contemporânea, a exemplo do consumo excessivo, velhas soluções não são mais compatíveis sob a perspectiva do acesso à justiça. A partir disso, em atendimento aos direitos fundamentais, defende-se a construção de um modelo adequado de proteção do consumidor em juízo, com as adaptações à realidade econômico-social e sobretudo com a recepção de novos espaços e mecanismos de solução de conflitos, a exemplo da autocomposição.

Palavras-chave: Acesso à Justiça. Superendividamento. Litigiosidade. Autocomposição.

\begin{abstract}
:
In the contemporary society, consumption and its excesses have affected the quality of life of the citizen, such the intervention of the economy in social and personal relations. Overindebtedness is the result of this interference and the cause of many other conflicts faced by the citizen. In this context, this paper proposes to evaluate the adversarial environment disciplined

1 Doutora em Direito pela UNISINOS, Mestre em Direito pela UNISINOS. É Professora Adjunta da Faculdade de Direito da Universidade Federal de Pelotas (UFPEL). E-mail: karinne.adv@hotmail.com

2 Mestre em Direito pela Universidade Federal de Pelotas (UFPEL). E-mail: anacarlabrin@hotmail.com
\end{abstract}


by the Procedural Code for the treatment of repetitive demands, applicable to repetitive consumption relations. In a second moment, the work tries to emphasize the autocomposition as an adequate space to deal with the conflicts supported by the over-indebted consumer. In this regard, the article highlights the Treatment Project for Super Indebtedness, headed by TJRS since 2006, as well as Bill 3515/2015, which is being negotiated in the Chamber of Deputies, both aimed to promote public policies in a multidisciplinary bias, highlighting consumer reeducation and conciliation as tools for overcoming the issues of over-indebtedness. For this, the article uses the hypothetico-deductive method and hopes to achieve, as possible analysis results, the demonstration that, for complex situations experienced by the contemporary society, like excessive consumption, old solutions are no longer compatible under the perspective of access to justice. Based on this, in compliance with fundamental rights, it defends the construction of an adequate model of consumer protection in court, with adaptations to the economic-social reality and, most of all with the reception of new spaces and mechanisms for the solution of conflicts, example of autocomposition.

Keywords: Access to justice. Over-Indebtedness. Litigiousness. Autocomposition.

\section{INTRODUÇÃO}

A pesquisa nacional de endividamento e inadimplência do consumidor revela que, para junho de 2018, 58,6\% das famílias brasileiras se declaram endividadas, das quais 23,7\% possuem contas em atraso e 9,4\% afirmam não ter condições de liquidar suas pendências. $\mathrm{O}$ cartão de crédito está disparado no ranking do endividamento, eis que responsável por $76,3 \%$ dos tipos de dívidas assumidas, enquanto o crédito consignado, outro vilão do comprometimento da renda, aparece em 5,5\% dos casos (BRASIL, CNC, 2018).

São inúmeras as causas do consumo excessivo, avaliação esta que exige uma análise complexa e que contempla aspectos psicológicos, socioeconômicos e principalmente políticos, dada a posição e o papel do Estado, ao lado do mercado e da sociedade, como atores indissociáveis e determinantes das relações sociais, econômicas e interpessoais na contemporaneidade. Para além das causas, os impactos do endividamento recaem não só sobre a renda do cidadão e de sua família como também comprometem o mínimo existencial, na expectativa de uma vida digna assim garantida constitucionalmente.

Por outro lado, é possível observar, de acordo com dados do Conselho Nacional de Justiça (CNJ), que os excessos do consumo acompanham igualmente os excessos da litigiosidade, razão pela qual é preciso avaliar se o espaço judicial para o qual desaguam os conflitos de endividamento e superendividamento oferece tratamento judicial adequado, notadamente sob a perspectiva da dignidade da pessoa humana (art. $1^{\circ}$, inciso III) e dos direitos fundamentais do acesso à justiça (art. $\left.5^{\circ}, \mathrm{XXXV}\right)$, devido processo legal (art. $\left.5^{\circ}, \mathrm{LV}\right)$ e da proteção especial do consumidor (art. $5^{\circ}$, XXXII e art.17o, inciso V).

Para tanto, é preciso considerar o perfil da litigiosidade e as perspectivas geradas pelos procedimentos disciplinados pelo Código de Processo Civil (CPC), no âmbito do contencioso, sobretudo, para tratar de demandas repetitivas, nas quais se enquadram os conflitos das relações de consumo, especialmente a partir do contingente de ações revisionais de contratos bancários que compõe o acervo do Judiciário estadual. Além disso, também é preciso considerar se rituais não adversariais, focados na autocomposição, possibilitam a recuperação do consumidor e estão aptos a prevenir novos endividamentos, através de medidas de prevenção e de emancipação do consumidor frente à sociedade do consumo. 
Assim, são objetivos do presente trabalho expor e avaliar o ambiente adversarial proposto pelo novo CPC no âmbito do modelo de julgamento de demandas repetitivas, aplicável às relações de consumo repetitivas, questionando sua constitucionalidade e sua natureza individualista, que sugere incompatibilidade para tratar conflitos de caráter coletivo e assim garantir a proteção do consumidor em juízo. Num segundo momento, o trabalho procura destacar a autocomposição como espaço adequado para tratamento dos conflitos suportados pelo consumidor superendividado, seja através da conciliação ou da mediação. Neste ponto, o artigo destaca o Projeto de Tratamento do Superendividamento, capitaneado pelo Tribunal de Justiça do Rio Grande do Sul desde 2006, bem como o Projeto de Lei no 3515/2015, com trâmite na Câmara dos Deputados e voltado à alteração do Código de Defesa do Consumidor, que adotam políticas de tratamento pautadas na reeducação do consumidor e na conciliação como ferramentas de superação do quadro de superendividamento.

Para tanto, o artigo vale-se do método hipotético-dedutivo e espera alcançar, como possíveis resultados de análise, a demonstração de que, para situações complexas vividas pela sociedade contemporânea, a exemplo do consumo excessivo, velhas soluções não são mais compatíveis sob a perspectiva do acesso à justiça. A partir disso, em atendimento aos direitos fundamentais, o estudo defende a importância da construção de um modelo adequado de proteção do consumidor superendividado, com as adaptações à realidade econômico-social e com a recepção de novos espaços e mecanismos de solução de conflitos, a exemplo da autocomposição.

\section{ESTADO, PODER ECONÔMICO E CIDADANIA}

A importância do crédito para a economia e o papel do Estado quanto à regulação do mercado não só influenciam na qualidade de vida do cidadão e de sua família como tornam o poder econômico e o Estado atores indissociáveis no processo de endividamento e sua forma mais voraz, o superendividamento.

Segundo García-Pelayo, a acumulação do capital e o aumento da produção à base de exploração do trabalho e de salários enxutos, em benefício de uma minoria, era a base do capitalismo clássico, enquanto o novo modelo capitalista (iniciado no século XIX e que se estendeu nas primeiras décadas do século XX), passou a apostar justamente no aumento do consumo das massas trabalhadoras. O crescimento da demanda era diretamente proporcional ao aumento do poder de consumo da população empregada, logo, o aumento vertiginoso do consumo será justamente o fôlego do capitalismo no decorrer do século XX (GARCÍA-PELAYO, 1982, p.67).

Sob outro aspecto, a moralização do lucro vai naturalizar o novo comportamento do mercado, o que, segundo Weber (2004, p.148), tem na ética protestante a sua grande contribuição, já que a "a riqueza, quando advém do desempenho do dever vocacional, é não só moralmente lícita, mas até mesmo um mandamento". Trata-se da construção de um momento histórico de valoração do capital, acúmulo de riqueza e futura produção em massa de produtos e serviços.

Ainda, nesse ambiente de início de século, eventos marcantes determinaram a ordem político-econômica para os anos seguintes. A Primeira Guerra Mundial em 1914, a Constituição Mexicana e a Revolução Russa em 1917, a Constituição alemã de Weimar de 1919, a crise econômica de 1929 e as medidas político-econômicas de contenção, a exemplo do New Deal e o keynesianismo norte-americanos, e do Plano Beveridge na Alemanha, definitivamente irão redesenhar o cenário mundial após a Segunda grande guerra. 
Nessa linha, a segunda metade do século passado será caracterizada pela democratização das sociedades e a remodelação do conceito de cidadania no âmbito dos direitos humanos, sobretudo a partir do fortalecimento do Estado intervencionista, muito embora a superveniência da identidade de um Estado de Bem-Estar Social (Welfare State) venha revelar, na verdade, uma estratégia de autodefesa ou sobrevivência do liberalismo econômico, com forte manipulação do Estado para o crescimento da economia de mercado.

A partir dos anos 70 do século XX, a mundialização da economia impacta em definitivo o perfil do Estado, que passa a ajustar a sua estrutura e a adaptar as suas funções ao novo mundo globalizado. No ruir das certezas da modernidade, cresce o espaço nobre encontrado pela economia, que encontra um Estado mutante, em plena crise de identidade. O Estado perde sua autoridade e torna-se incapaz de impor soluções, e a insurgência da economia global, a partir da derrocada do bloco socialista, passa a determinar um novo tipo de relação entre os Estados nacionais, qual seja a de interdependência e de influência sobre sua política interna (ROTH, 1996), o que notadamente mostra-se fatal para a compreensão de soberania, nacionalidade e cidadania a partir de então.

No final do século XX o cenário, portanto, é de intensa transformação. A economia de mercado, agora de cunho neoliberal, revela sua autonomia e capacidade de autorreprodução do capitalismo financeiro. É o momento de impor suas diretrizes e guiar o Estado e a sociedade. Para Ha-Joo Chang, nos últimos 30 anos, o sistema capitalista se fortalece com seu formato neoliberal, que preza pelo lucro a curto prazo e sem qualquer reinvestimento no crescimento global. O capitalismo abandona a produção, atrelada ao Estado, pois não depende mais da atuação estatal para a sua mantença. O capital passa a ser autossustentável e autorreprodutivo, pois sobrevive do lucro (CHANG, 2013, p.35). Um verdadeiro "triunfo do capitalismo" (TOURAINE, 2007, p.37).

Mas notadamente essa constante transformação não ocorre de forma linear, já que sua intensidade, que sugere a formação de um novo perfil de Estado, ocorre da medida da historicidade e da cultura de cada país. A intervenção estatal, neste sentir, visa propositadamente desregular os mercados de forma seletiva e descontinuar o Estado do bem-estar social com diferentes intensidades e orientações, a depender da natureza das forças e instituições políticas de cada sociedade (CASTELLS, 2017, p. 61), consagrando, nas palavras de Jacques Chevallier (2009, p.277) um Estado em mutação que possui uma forma política ambígua e, transitando em incertezas, que converge para uma concepção diversa de organização política, rompendo totalmente com a racionalidade estatal ínsita à modernidade.

O fato é que a economia, agora como forte protagonista, passa a sujeitar o Estado às suas diretrizes, interferindo na regulamentação de direitos e impactando a vida do cidadão. Especialmente em solo brasileiro, em que pese a Constituição Federal tenha guardado um sentido protecionista ao cidadão ao lhe conferir amplos direitos sociais, o que se tem, em verdade, é a consagração de várias reformas constitucionais que suportaram a confluência ao projeto neoliberalista, alterando sobremaneira a configuração inicial da noção de cidadania dada pelo processo de redemocratização.

Assim, levando-se em consideração que esta noção nunca esteve atrelada a uma verdadeira conquista (CARVALHO, 2016, p. 219), mas tão somente a uma concessão de direitos por parte do Estado, o neoliberalismo imporá "uma concepção restritiva à noção de cidadania, diminuindo seus espaços, reduzindo seus direitos e moldando-a ao mercado" (BELLO, 2011, p. 76).

O resultado de tamanha intervenção é o desmantelamento dos direitos fundamentais e a criação de um cenário de comprometimento dos valores constitucionais, desencadeando um processo de desigualdade social cada vez mais acentuada. 


\section{CONSUMO E (SUPER) ENDIVIDAMENTO NO BRASIL}

A pesquisa nacional de endividamento e inadimplência do consumidor revela que, para junho de 2018, 58,6\% das famílias brasileiras se declaram endividadas, das quais 23,7\% possuem contas em atraso e 9,4\% afirmam não ter condições de liquidar suas pendências. $\mathrm{O}$ cartão de crédito está disparado no ranking do endividamento, eis que responsável por $76,3 \%$ dos tipos de dívidas assumidas, enquanto o crédito consignado, outro vilão do comprometimento da renda, aparece em 5,5\% dos casos (BRASIL, CNC, 2018).

Outro dado relevante no mesmo período é o fato de que os índices de comprometimento da renda não apresentam diferenças significativas entre a população que recebe até dez salários mínimos e a população que possui renda acima desse patamar. No primeiro grupo, $60 \%$ das famílias encontram-se endividadas, percentual este que fica em $52 \%$ para a população cuja a renda supera dez salários mínimos.

Ainda, se considerado o tipo de dívida a ser enfrentada, os percentuais são muito similares. No cartão de crédito, $77,3 \%$ das famílias com renda até dez salários mínimos estão comprometidas, o que nas famílias com renda acima de dez salários corresponde a $72,4 \%$. O percentual também é muito similar nas dívidas com crédito consignado: no primeiro grupo é de $5,2 \%$ e no segundo é de $6,7 \%$.

\subsection{O ocorre no Brasil?}

Primeiramente, observa-se um avanço da classe média no período entre 2001 e 2011, que sai de um patamar de $38 \%$ para $53 \%$ do total da população, concentrada especialmente na área urbana da região sudeste e nos segmentos da indústria e comércio. A classe baixa, por sua vez, está concentrada em boa parte na região norte do país. Esse avanço do poder aquisitivo tem participação expressiva no consumo das famílias, deixando o Brasil posicionado em $8^{\circ}$ lugar no mercado consumidor, logo após a Itália (BRASIL, 2012, p.20).

Por outro lado, dentro deste mesmo período, observa-se que a rede bancária registrou, de 2001 a 2007, um aumento de 57,5\% no número de contas correntes, evoluindo de 43,3 milhões para 62,8 milhões. Aliado a isso, o Estado atuou fortemente neste período através de políticas econômicas de facilitação de acesso ao crédito. A Lei no 10.735/2003, passou a estimular a bancarização para a população de baixa renda através de microcréditos. A Lei 10.820/2003, por sua vez, possibilitou o acesso ao crédito através de pagamento consignado nos salários e proventos de aposentadoria, servindo de grande estímulo à tomada de crédito. (BARONE; SADER, 2008, p.1252 e 1258). Os Bancos públicos (CEF e Banco do Brasil) foram chamados à "bancarizar" a população de baixa renda, de modo que a inclusão de uma grande massa de pessoas no sistema financeiro nacional passou a ser a tônica principal das políticas públicas de acesso ao crédito nesse período (BARONE; SADER, 2008, p.1253).

Sob outro aspecto, de acordo com o Instituto de Pesquisa Econômica Aplicada (IPEA), no período entre dezembro de 2003 e dezembro de 2010, a concessão de crédito à pessoa física elevou o PIB nacional de 9 para 21 pontos percentuais. A diminuição de risco para os bancos, a redução das taxas de juros, o alongamento do prazo de financiamento e o aumento do volume de crédito financiado contribuíram sobremaneira para a oferta ostensiva de crédito. $\mathrm{O}$ crédito consignado, o financiamento de veículos e à venda à vista por meio de cartão de crédito são segmentos que explicam quase a totalidade do incremento de 8,2 para 8,7 pontos percentuais do PIB neste período (MORA, 2015, p.13-14). 
Para Francisco Marcelo Barone e Emir Sader (2008, p.1264), o acesso ao crédito para consumo incentiva a população a consumir, mas não gera empregos para a população de baixa renda, dado os níveis precários de escolarização. Para esse público, "são necessárias políticas públicas integradas de crédito para produção, de maneira a desenvolver seus negócios, e de outras ações, tais como capacitação, assistência técnica e acesso a mercados".

Atualmente, o quadro pode ser confirmado pelos dados do IBGE de 2017. Fatores econômicos como o aumento do endividamento e a redução dos investimentos, associados à crise política, especialmente nos últimos dois anos (2015/2016), impactam no aumento da desocupação, na interrupção do crescimento dos empregos com vínculo formal de trabalho e aumento de trabalhadores por conta própria (IBGE, 2017, p.16), o que compromete a perspectiva de renda a longo prazo e, por consequência, compromete a qualidade de vida do cidadão e de sua família.

Neste sentido, é possível afirmar que a concessão ostensiva do crédito, aliado à lógica neoliberal de que o consumo seduz pela sensação de "poder sobre si" (LIPOVETSKY, 2017, p.51) na medida em que este ilude o cidadão acerca de sua individualidade e autonomia, justifica a explosão do consumo e, com ele, do superendividamento.

O superendividamento, assim, pode ser definido pela "incapacidade do devedor de pagar todas as suas dívidas, atuais e futuras, com seu patrimônio e seu rendimento", seja qual for seu rendimento ou sua profissão, (LIMA, 2014, p.34), e decorre da concessão desmedida ou irresponsável do crédito e da ausência de regulação do mercado e da ausência do Estado provedor (educação, emprego etc.) (LIMA, 2014, p.35), vulnerabilizando o consumidor e onerando sua família.

Com vistas à proteção do consumidor superendividado, encontra-se em tramitação na Câmara dos Deputados o projeto de lei no 3515/2015, que pretende alterar o Código de Defesa do Consumidor. Segundo o texto do projeto, na inserção do art.54-A, nos parágrafos $1^{-}$e $2^{\circ}$, superendividamento é a impossibilidade manifesta de o consumidor, pessoa natural, de boa-fé, pagar a totalidade de suas dívidas de consumo, exigíveis e vincendas, decorrentes de quaisquer compromissos financeiros assumidos, inclusive operações de crédito, compras a prazo e serviços de prestação continuada, sem comprometer seu mínimo existencial.

Nesse universo, o conflito social decorrente do endividamento é inevitável, seja no aspecto psíquico, seja no âmbito das relações pessoais, impactando negativamente sobre as relações familiares (MIRAGEM; LIMA, 2014, p.95), sobre o desenvolvimento dos filhos (LIMA, 2014, p.40) e, inclusive está associado ao aumento da violência doméstica (HOFMEISTER, 2015), uma vez que o problema gerado pelo endividamento ou pelo superendividamento, sua forma mais opressora, é sistêmico, afetando o cidadão e todos que com ele convivem.

É no Judiciário que tal conflituosidade vai desaguar, o que pode ser confirmado pelo quadro de litigiosidade que a seguir será retratado, denotando, assim, o custo social decorrente da ostensividade do poder econômico financeiro sobre a sociedade, a partir do vácuo deixado pelo Estado e da ausência de políticas públicas reguladoras.

\section{O PERFIL DA LITIGIOSIDADE}

Segundo o Relatório 100 Maiores Litigantes do Conselho Nacional de Justiça (2010 e 2012), observa-se uma evidência acerca da litigiosidade nas relações de consumo, a partir da frequência com que Bancos e Telefonia frequentam os processos judiciais. Na primeira edição, a pesquisa considerou os processos já existentes. Na segunda, tomou-se como amostra os processos ingressantes no ano de 2011. 
No Relatório de 2010, o 2⿳ㅡㄹ lugar geral dos maiores litigantes é ocupado pelos Bancos (54\%). O ramo da telefonia aparece em $4^{\circ}$ lugar (9,6\%). Como se observa, no âmbito privado, Bancos e Telefonia ocupam juntos $64 \%$ do total de processos envolvendo litígios bancários e de telefonia. Além disso, quatro grandes grupos financeiros constam como sujeitos processuais em cerca de $75 \%$ dos processos dos 100 maiores litigantes da Justiça Estadual. Em 48\% dos casos, os Bancos são demandados, enquanto que as telefonias ocupam lugar assíduo no polo passivo em $77 \%$ dos processos.

No Relatório de 2012, outra amostra pode ser obtida nos Juizados Especiais Cíveis da Justiça Estadual. Neste âmbito da justiça, Bancos e Telefonia aparecem no $1^{\circ}=(14,7 \%)$ e $2^{\underline{0}}$ $(8,3 \%)$ lugares, respectivamente. Essa contingência também é confirmada pelo número de reclamações nos Procons do país no ano de 2012, relacionadas a aparelhos celulares (BRASIL, Ministério da Justiça 2012, p. 9).

O Relatório Justiça em Números do CNJ também confirma essa contingência. Desde o Relatório de 2015, estão categorizadas as demandas mais recorrentes por assunto e classe, por jurisdição. Na justiça estadual, onde as relações de consumo se destinam por força da competência, todos os relatórios, para os exercícios de 2014 a 2016, apontam pela recorrência das relações de consumo, conforme pode ser observado no quadro a seguir.

Litigiosidade na Justiça Estadual. Quadro Geral. 2014 a 2016*.

\begin{tabular}{|c|c|c|}
\hline POSIÇÃO & ÁREA & ASSUNTO \\
\hline $\mathbf{1}^{\circ}$ lugar & DIREITO CIVIL & Obrigações/Espécies de Contratos \\
\hline $2^{\circ}$ lugar & DIREITO DO CONSUMIDOR & $\begin{array}{c}\text { Responsabilidade do Fornecedor/Indenização por Dano } \\
\text { Moral }\end{array}$ \\
\hline $3^{\circ}$ lugar & DIREITO TRIBUTÁRIO & Dívida Ativa \\
\hline $4^{\circ}$ lugar & DIREITO CIVIL & Responsabilidade Civil/Indenização por Dano Moral \\
\hline $5^{\circ}$ lugar & DIREITO CIVIL & Família/Alimentos \\
\hline
\end{tabular}

Fonte: CNJ. Relatório Justiça em Números.

* Apenas em 2014, 4 e 5을 lugar se invertem.

O quadro é ainda mais acentuado no âmbito dos Juizados Especiais, notadamente pela abrangência da sua competência:

Litigiosidade nos Juizados Especiais Estaduais. Quadro Geral. 2014 a 2016*.

\begin{tabular}{|c|c|c|}
\hline POSIÇÃO & ÁREA & ASSUNTO \\
\hline $\mathbf{1}^{\circ}$ lugar & DIREITO DO CONSUMIDOR & $\begin{array}{c}\text { Responsabilidade do Fornecedor/Indenização por Dano } \\
\text { Moral }\end{array}$ \\
\hline $2^{\circ}$ lugar & DIREITO CIVIL & Responsabilidade Civil/Indenização por Dano Moral \\
\hline $3^{\circ}$ lugar & DIREITO CIVIL & Obrigações/Espécies de Títulos de Crédito \\
\hline $4^{\circ}$ lugar & DIREITO CIVIL & Obrigações/Espécies de Contratos \\
\hline $5^{\circ}$ lugar & DIREITO DO CONSUMIDOR & $\begin{array}{c}\text { Responsabilidade do Fornecedor/Indenização por Dano } \\
\text { Material }\end{array}$ \\
\hline
\end{tabular}

Fonte: CNJ. Relatório Justiça em Números.

* Apenas em 2014, Direito Civil - Contratos ocupa o 3 o lugar.

Por outro lado, é preciso considerar ainda que o acesso à justiça é desigual, na medida em que as estatísticas sinalizam para o exercício do direito de ação proporcional ao poder aquisitivo, pois o custo do processo ainda é um obstáculo que boa parte da população não pode suportar (SOUZA SANTOS, 2008, p.17o). Confirma essa hipótese o fato de que o maior número de demandantes na justiça estadual está concentrado nas regiões sudeste e sul, onde justamente 
se concentra a classe média, enquanto que na região norte e nordeste, com predominância da classe baixa, a litigiosidade é em menor número (SANTOS, 2016, p. 68).

Por fim, em 2011, a PUC/PR divulgou pesquisa encomendada pelo CNJ que confirmou a concessão e tomada de crédito como a principal causa do progressivo aumento de demandas judiciais de massa, nas quais as ações revisionais estão inseridas dada a frequência de litigância das instituições bancárias (CNJ, 2011).

Em última análise, portanto, as pesquisas complementam-se e convergem para o fato de que os dados da litigiosidade no país estão intimamente ligados à concessão do crédito de forma desmedida, resultando na evolução do consumo e seus excessos. Tal litigiosidade, no âmbito das relações de consumo, submete o consumidor a duas situações desfavoráveis frente aos fornecedores de serviços: na primeira, na via administrativa, o cidadão suporta a ausência da regulação estatal, o que favorece a atuação livre e ostensiva do mercado; na segunda, já no âmbito do Judiciário, o cidadão, igualmente desamparado, tem buscado individualmente soluções de um litígio que, na verdade, tem natureza coletiva. (SANTOS, 2016, p. 71).

É preciso lembrar que o PROCON não está presente por todas as veredas do país, assim como sua presença não garante por si só a proteção especial que o consumidor superendividado necessita receber. E na esfera judicial? $\mathrm{O}$ aparato jurisdicional está preparado para tratar adequadamente dos conflitos decorrentes das relações de consumo relacionadas ao superendividamento? É o que se pretende enfrentar no capítulo a seguir.

\section{O MODELO DE JULGAMENTO DE DEMANDAS REPETITIVAS NO CPC: UMA AMOSTRA DO RITUAL ADVERSARIAL DE SOLUÇÃO DE CONFLITOS}

O contencioso judicial, na década de 90 e no início dos anos 200o, ocupou significativamente os gabinetes do Judiciário no país, mormente em decorrência da avalanche das ações revisionais de contrato bancário (CNJ, 2011).

Ainda sob a vigência do Código de Processo Civil de 1973 algumas medidas foram adotadas para conter essa litigiosidade, a exemplo da inserção dos artigos 285-A e 543-C, a partir das Leis 11.277/2006 e 11.672/2008, que instauraram o início de uma lógica de procedimento voltado para demandas repetitivas. Sentenças de improcedência reproduzidas em processos que dispensam a citação do réu e recursos especiais paradigmas julgados por amostragem, em meio à multiplicidade de recursos, foram a tônica dessa lógica.

O Código de Processo Civil de 2015, por sua vez, a pretexto de assegurar a isonomia e segurança jurídica, instaura uma sistemática de uniformização de julgamentos de demandas repetitivas, devidamente modelada para fortalecer a jurisprudência dos tribunais superiores, numa verdadeira operação de mecanização da prestação jurisdicional. Integram esse modelo, nos termos do art.928 do CPC, os recursos especial e extraordinário repetitivos (art.1036 ao art.1041) e o Incidente de Resolução de Demandas Repetitivas IRDR (art.976 ao art.987) todos do referido Código.

Ocorre que, nesse ambiente adversarial, as demandas bancárias, nas quais o consumidor busca a revisão do contrato ou a partir dele é executado, além de representarem um alto custo para o Poder Judiciário, não resolvem a questão social do superendividamento.

Nesse sentido, para Clarissa Costa de Lima (2014, p.134-135),

A perspectiva individual que caracteriza as ações revisionais não permite o tratamento de todos os efeitos do superendividamento que extrapolam o equilíbrio econômico do contrato. Na revisão, o juiz examina as cláusulas contratais sem se preocupar com o passivo do devedor ou com o restante das dívidas assumidas, pois se objetivo não é 
reabilitar financeiramente o consumidor, mas apenas restaurar o equilíbrio econômico do contrato em exame.

O fato é que, além de perfumar a solução do problema relacionado à litigiosidade de massa, o procedimento eleito pelo CPC para tratamento da litigiosidade de massa revela-se como um grande risco de precarização da prestação jurisdicional, seja pela abstração dos julgados, seja pela abertura para a discricionariedade, seja pela autoridade "não autorizada". Na contramão da tradição (GADAMER, 2004, p.388) tal modelo de julgamento de demandas repetitivas subjuga elementos fundantes da jurisdição, desrespeitando o devido processo legal e, a partir disso, deixa de proporcionar acesso à justiça adequado.

O IRDR tem inspiração na experiência da causa-piloto do direito alemão (Musterverfahren). Contudo, na Alemanha, o ritual foi experimental, idealizado em 2005 e posteriormente prorrogado até dezembro de 2012, para aplicação restrita aos casos de grupos lesados no mercado de capitais (AMARAL, 2013, p.63-64). É por essa razão que tal procedimento não encontra similar em nenhum outro sistema processual ocidental (NERY; NERY JR, 2016, p. 2.112). No Brasil, o Incidente pretende coletivar o julgamento restrito a questões de direito, decorrentes de demandas repetitivas.

Trata-se de técnica que possui a finalidade de gerenciar a litigiosidade repetitiva já em tramitação e formar precedentes para casos futuros (NUNES; VIANA, 2018, p.282). De acordo com os artigos 985 e 987 do CPC, o incidente é instaurado no Tribunal de Justiça ou Regional e produzirá decisão com efeito vinculante e erga omnes para os processos suspensos e futuros, no âmbito da jurisdição do tribunal, sob pena de Reclamação (art.985, §1o do CPC) e, caso o mérito do incidente seja objeto de recurso especial e extraordinário, a tese jurídica firmada terá aplicação em todo o território nacional.

Ainda na comparação com o instituto alemão, enquanto o Musterverfahren se propõe à análise de teses jurídicas e aspectos fáticos da questão repetitiva, no Brasil o Incidente está restrito às questões de direito (art.976, inciso I do CPC), o que demonstra as dificuldades pátrias de superação de uma racionalidade apegada à diferença entre questão de fato e questão de direito (SANTOS, 2006), há tempos já denunciada por Castanheira Neves (1967, p. 331) e Ovídio Baptista da Silva (1997, p.126).

Nessa linha, o sacrifício do caso concreto é justamente a base do discurso arbitrário a pretexto de conferir efetividade à prestação jurisdicional, impedindo que a decisão jurídica seja produto de revelação como faticidade (STRECK, 2009, p.170).

Não bastasse isso, é questionável também o atendimento dos propósitos que ensejaram a adoção do procedimento frente à massificação dos conflitos. Primeiro, considerando que o Incidente venha a afetar processos em trâmite, não impedirá a propositura de novas ações idênticas. Segundo, é justamente a propositura de novas demandas individuais que enseja a aplicação da tese jurídica consolidada pela decisão dita vinculante, ou seja, é preciso litigar para a aplicação da tese abstrata e se esta for desfavorável, ensejará o encerramento através da improcedência liminar (art.332, incisos II e III do CPC).

Trata-se de técnica que cria um verdadeiro arcabouço de respostas formuladas e prontas antes das perguntas (STRECK; ALVIM; LEITE, 2016), como los modelos previstos en el fichero de Calamandrei (1960, p.70-71).

Os recursos especial e extraordinário repetitivos, por sua vez, serão utilizados, de acordo com o art.1036, quando houver multiplicidade de tais recursos com fundamento em idêntica questão de direito. Assim ocorrendo, observado o disposto no Regimento Interno dos respectivos tribunais superiores, serão escolhidos dois ou mais recursos representativos da controvérsia, afetando os recursos de processos individuais e coletivos pendentes de julgamento nos tribunais de origem. 
Tal modelo não se sustenta, eis que passível de questionamento a partir de, no mínimo, três situações: a primeira, é a de sua abstração, campo fértil para a subsunção de arbitrariedades (SANTOS, 2016, p.250); a segunda, é da inconstitucionalidade do seu poder de vinculação, sem qualquer previsão constitucional (Nelson Nery Jr e Georges Abboud, entre outros) e, a terceira, é do tratamento individual dado a demandas de natureza coletiva (SANTOS, 2016, p.238-239).

Em sede de julgamento de casos repetitivos, suas decisões paradigmas são abstratas, utilizadas como verdadeiros instrumentos de mecanização da prestação jurisdicional a casos futuros supostamente idênticos. Ainda que tal modelo queira se legitimar pelos parágrafos primeiro e segundo do mesmo art.927, no sentido de que as suas decisões respeitem o contraditório e a correta fundamentação, além da possibilidade de revisão, é preciso reconhecer que, nos assombros dos gabinetes assoberbados de processos, a meta é dar cabo dos litígios em excesso por jurisdição express, desapegadas do caso concreto.

Trata-se de uma opção por uma jurisdição conceitual que não pretende de fato enfrentar o caso concreto e que busca a abstração para fertilizar os decisionismos discricionários e arbitrários, ao gosto do intérprete, através de julgamentos por amostragem (SANTOS, 2016, p.276). É tempo de mecanizar a prestação jurisdicional.

A segunda crítica vem argumentada na inconstitucionalidade do modelo, defendido com autoridade de vinculação sobre a jurisdição inferior. De acordo com o art.927, inciso III do CPC, os juízes e tribunais observarão os acórdãos em incidente de resolução de demandas repetitivas e em julgamento de recursos extraordinário e especial repetitivos. Luiz Guilherme Marinoni (2011, p.240) e Daniel Mitidiero (2017, p.90), ao conceituarem precedentes, defendem como razões jurídicas necessárias e suficientes que resultam da justificação das decisões provenientes das Cortes Superiores, e por essas razões são sempre vinculantes. Muito embora os autores também defendam uma distinção entre súmulas, jurisprudência, jurisprudência dominante e enunciados, cujos conceitos ficam embaçados na linguagem do art.927, o fato é que Marinoni e Mitidiero acabam reforçando a ideia de vinculação dos pronunciamentos ali mencionados. Marinoni (2011, p.144-145) defende que é irracional deixar de aplicar o "precedente" em caráter obrigatório para admitir interpretação distinta daquela proferida por órgão cuja finalidade, nos termos da Constituição Federal, é justamente de conferir unidade do direito federal. Para Daniel Mitidiero (2017, p.84-85), existe no direito brasileiro um forte efeito vinculante dos precedentes, pois os juízes têm o dever de mencionar e analisar os precedentes existentes sobre o caso, com dever de segui-los, ainda que não concordem com suas razões, deles apenas podendo se afastar para superá-los, se tiverem competência para tal.

Mas a questão não reside na técnica em si, mas sim na ordem de vinculação ordenada pelo CPC sem qualquer antecipação constitucional para tal. É o CPC, como lei ordinária, que atribui tamanha autoridade a todos os institutos do art.927.

Para Nelson Nery Jr. (2016 p.1963-1964), a autoridade de vinculação somente se coloca para as decisões do STF proferidas em controle concentrado de constitucionalidade e para as súmulas vinculantes, previstos nos incisos I e II do art.927 do CPC, nos termos da Constituição Federal no art.102, parágrafo $2^{\circ}$ e art.103-A. Neste sentido, a vinculação a preceitos abstratos com características de leis somente pode adquirir autoridade de vinculação a partir da própria Constituição e, inexistindo até o momento previsão constitucional para tal, é inconstitucional a previsão contida no art.927, incisos III ao V do CPC, principalmente por desrespeito ao devido processo legal (NERY JR, 2016, p.1963). Nessa mesma linha, Georges Abboud e Marcos Cavalcanti defendem ainda a inconstitucionalidade do IRDR por violar a independência funcional dos magistrados e à separação funcional dos poderes; por violar o contraditório, uma vez ausente o controle judicial da adequação da representatividade como pressuposto fundamental para a eficácia vinculante da decisão de mérito desfavorável aos processos dos 
litigantes ausentes do incidente processual coletivo; por violar o direito de ação, por ausência de revisão do direito de o litigante requerer sua autoexclusão (opt-out) do julgamento coletivo; e, por fim, por violar o sistema de competências da Constituição quando o procedimento é estendido aos juizados especiais (ABBOUD; CAVALCANTI, 2015).

Por outro lado, tampouco é possível afirmar que os arts.926 e 927 tornam mais visível o stare decisis no Brasil (MITIDIERO, 2017, p.82), na medida em que, enquanto o stare decisis aposta no caso concreto e na qualidade, o IRDR vai na linha do julgamento em teses abstratas e na quantidade, ou seja, enquanto o stare decisis é um aperfeiçoamento histórico, o IRDR é uma originalidade inconstitucional (ABBOUD; CAVALCANTI, 2015).

Por fim, a terceira crítica a ser colocada é quanto à desigualdade instaurada pelo Código, quando este "perde a oportunidade" de disciplinar o processo coletivo, optando justamente por um modelo individualista de repetitividade para tratar da indesejada litigiosidade de massa, ferindo a isonomia entre rito (individual) e conflito (coletivo) (SANTOS, 2016, p.242). $\mathrm{O}$ veto ao art.333, que previa a conversão de demandas individuais em ação coletiva, é uma máxima dessa lógica (SANTOS, 2016, p.132). A pretexto de conferir segurança jurídica, criase um discurso retórico por meio de uma lógica utilitarista ${ }^{3}$, a fim de dar cabo dos excessos da indesejada litigiosidade repetitiva (SANTOS, 2016, p.246). Trata-se de uma clara estratégia para inibir o acesso à justiça pleno, através de decisões vinculantes colocadas como respostas prontas e prévias à própria postulação em juízo. Pouco ou quase nada se ganha em termos de democracia, se uniformizarmos decisões a partir de julgados discricionários, tão somente porque provenientes dos Tribunais (NERY JR; ABBOUD, 2013).

Logo, a lógica instaurada pelo art.927, inciso III, no julgamento das demandas repetitivas, torna a jurisdição inferior e refém dos provimentos vinculantes. É o regozijo da subsunção da controvérsia às decisões abstratas e arbitrárias, afeitas ao positivismo normativista (SANTOS, 2016, p.125). Engessa o sentido no processo de compreensão, descaracterizando a sua essência e desviando o intérprete de sua consciência histórica efectual (GADAMER, 2004, p.492). Fere o exercício pleno do acesso à justiça, previsto no art. 5ㅜㅗ inciso XXXV da CF, sobretudo quando viola elementos básicos do devido processo legal, tão caros para uma frágil democracia.

Logo, o modelo sob análise - cujo procedimento de demandas individuais, além de incompatível com o caráter coletivo da litigiosidade de massa, nas quais se incluem as demandas de consumo, especialmente as ações revisionais de contrato bancário - não está adequado ao modelo constitucional de jurisdição, de modo que a reforma processual poderia ter apostado na adequação do rito à litigiosidade, instigando, recriando e reforçando uma cultura adequada de tratamento do conflito coletivo, na perspectiva do acesso à justiça.

É por essa razão que se torna necessário olhar para outras perspectivas de tratamento de conflito, na medida em que o procedimento judicial contencioso não demonstra qualquer adequação entre rito e conflito. Segundo Cláudia Lima Marques (BRASIL, Ministério da Justiça, 2010, p.131):

A atuação eficaz do Estado-Juiz não encontra mais espaço no enfrentamento dos processos singulares, cujos litígios são adstritos às relações negociais isoladas e pontuais, sem a consideração da massificação do crédito e, atualmente, de muitas falências pessoais.

Como se observa, a clássica concepção de heterocomposição, seja ela considerada na esfera do tratamento individual da solução do conflito ou no âmbito do IRDR, requer a

3 Neste sentido tem-se Oscar Chase (2014, p. 23): "O poder, também, é sempre um problema quando os processos de resolução de conflitos são desenvolvidos, empregados, provocados e reformados. Modos de resolução de litígios nunca são neutros em relação aos indivíduos em disputa. Quem decide litígios, e os mecanismos que eles usam para decidir, privilegiará ou prejudicará diferentes setores da sociedade." 
intervenção de uma autoridade que, ao se substituir às partes conflitantes, impõe-se sobre elas e entrega a sua decisão com vistas à resolução do conflito. O caráter de substitutividade que lhe acompanha define a presença de um terceiro que se coloca sobre as partes e sobre elas ordena sua decisão (CHIOVENDA, 1998, p.8). Neste cenário, rituais dialogais, focados no consenso, são estranhos à cultura beligerante de solução de conflitos.

Nessa perspectiva, considerando que os rituais de resolução de litígios são um reflexo da cultura em que estão inseridos, não como um sistema autônomo ou produto de especialistas e experts isolados, mas como mecanismos através dos quais a vida social e cultural é mantida, provocada e alterada (CHASE, 2014, p.21) a autocomposição, a seguir analisada, vem com a proposta de observar o tratamento das demandas de consumo sob o enfoque do diálogo, apresentado como instrumento capaz de oferecer acesso à justiça adequado aos conflitos decorrentes das relações de consumo.

\section{O SUPERENDIVIDADO NOS CAMINHOS DA AUTOCOMPOSIÇÃO}

Com a proposta de desenvolver outros meios de solução de conflitos, Francesco Carnelutti desenvolveu sua teoria sobre os chamados equivalentes jurisdicionais, dentre os quais se encontra a autocomposição (1959, p.109). No México, Zamora y Castillo (1991, p.24 e 71) avança na doutrina do processualista italiano para colocar a autocomposição ao lado da jurisdição e da autotutela como meios igualmente legítimos de solução de conflitos.

No Brasil, Petrônio Calmon (2015, p.78-79) compreende a autocomposição como um meio de solução de conflito de aspecto multidisciplinar, na medida em que envolve o estudo de perspectivas provenientes da antropologia, da comunicação, da tomada de decisão, ou ainda gerenciais, sociológicas e psicológicas, dentre outras, abrangendo ciências variadas envolvidas na análise do conflito e em suas possíveis soluções.

Entre diversas nomenclaturas utilizadas para designar a materialização da autocomposição (meios, métodos, mecanismos ou formas), é possível apresentar a negociação, a mediação e a conciliação como os principais mecanismos para a obtenção da autocomposição (CALMON, 2015, p.87).

No atual Código de Processo Civil, a mediação é indicada especialmente para os

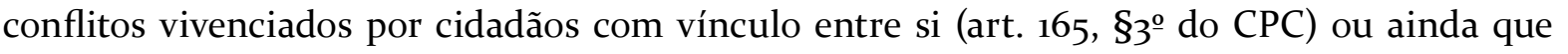
experimentam relações continuadas e que possivelmente podem perdurar após a ocorrência do conflito, a exemplo dos laços familiares e das relações de vizinhança. Trata-se da intervenção de um terceiro imparcial e neutro, sem qualquer poder de decisão, que auxilia os sujeitos do conflito a alcançar voluntariamente uma solução aceitável para ambos (CALMON, 2015, p.111). Na mediação, para além do acordo, o procedimento preocupa-se com o bem-estar das relações, a fim de que estas possam prosseguir transformadas em algo mais positivo e benéfico para os seus membros.

A conciliação, de viés mais prático, está especialmente voltada para as relações sem vínculo (art. 165, $\S^{2}{ }^{\circ}$ do CPC). O acordo é a principal finalidade e o conciliador manifesta sua opinião sobre a solução mais justa para o conflito (CALMON, 2015, p.139-140).

No CPC, a função de conciliar as partes também é do magistrado (art. 139, inciso V). Contudo, a norma vem acrescida de uma significativa predileção, qual seja a de que a autocomposição seja promovida "preferencialmente com auxílio de conciliadores e mediadores judiciais", assim designados pelo mesmo diploma legal, a partir do art.165.

É nessa perspectiva que o atual CPC coloca o consenso como norma fundamental do processo. $\mathrm{O}$ art. $3^{\circ}, \S 3^{\circ}$ impõe a justiça consensual como um verdadeiro compromisso para a 
magistratura, ministério público e advocacia pública e privada, com vistas ao desenvolvimento de uma justiça consensual, o que redireciona, inevitavelmente, a atenção do acesso à justiça para um ambiente não contencioso, que deverá fortalecer a autocomposição tanto no espaço judicial como extrajudicial. O consenso é, portanto, norma fundamental do direito processual, e não mais uma mera alternativa de acesso à justiça, razão pela qual vem modificado o conceito de citação (art.238 do CPC) e a audiência do art.334 do CPC torna-se o ato processual que sucede a propositura da petição inicial no rito comum.

Como se observa, o Código de Processo Civil expressa políticas públicas que buscam, qualificar o acesso à justiça a partir do estímulo ao diálogo e da solução dos conflitos por meio da autocomposição, na linha da Resolução 125/2010 do CNJ, impactando sobremaneira o paradigma da heterocomposição e rompendo com a lógica dos meios adversariais e polarizados de solução de conflitos, nos quais a satisfação de uma das partes implica necessariamente a insatisfação da outra (WARAT, 1999, p.16) e onde a sucumbência, uma constante, não assegura a pacificação do problema (ALCALÁ-ZAMORA Y CASTILLO, 1991, p.238).

Contudo, o procedimento consensual não prevê tratamento específico para os casos de superendividamento, de modo que é nesse ambiente adversarial que se encontram as demandas revisionais de contratos bancários, propostas por consumidores endividados ou superendividados, sobre as quais a lógica das demandas repetitivas vem sendo aplicada, de modo que as demandas desta natureza, então campeãs de litigância conforme já apontado anteriormente, recebem tratamento inadequado na via adversarial.

Veja-se que, como se não bastasse o fato de se tratarem de conflitos de natureza coletiva sendo tratados por meio de procedimento individualista, estão submetidos ainda a uma jurisprudência pátria que não revisa juros e que reforça princípios liberais como o pacta sunt servanda e da autonomia da vontade (LIMA, 2014, p.133-134). ${ }^{4} \mathrm{O}$ tratamento pela via adversarial, portanto, além de não pacificar a essência do problema, sequer possibilita a adoção de medidas preventivas de reeducação ${ }^{6}$ do consumidor. Longe disso.

Já no âmbito da autocomposição, os próprios sujeitos envolvidos no conflito são estimulados a construir alternativas de transformação do conflito e buscar em cooperação uma possível solução em torno do consenso. É o diálogo que proporciona essa mudança de perspectiva do tratamento do conflito e inclusive da transformação das relações sociais.

Além disso, o tratamento do consumidor superendividado, através da autocomposição, tem a perspectiva de se apresentar mais célere do que o procedimento adversarial, o que vem em atendimento, inclusive, da duração razoável como pressuposto processual elementar na pacificação dos conflitos, tornando a autocomposição procedimento ainda mais eficaz, pois, quanto mais cedo a questão se resolver, menos impactos sobre o cidadão e sua família o superendividamento terá (BUCAR, 2017, p.173).

As práticas de mediação e de conciliação têm em seu ritual o lugar central da fala e da escuta, com o reconhecimento das responsabilidades recíprocas e com a gestão das emoções (ROSENBERG, 2006, p.42), restabelecendo, a partir disso, valores eventualmente esvaziados por ocasião do conflito, a exemplo do reconhecimento do outro, humanizando, portanto, o procedimento e o tratamento do conflito. No âmbito do superendividamento, essa perspectiva

4 Neste sentido David Harvey (2008, p. 194) é esclarecedor: "Viver sob o neoliberalismo significa também aceitar ou submeter-se a esse conjunto de direitos necessários à acumulação do capital. Vivemos, portanto, numa sociedade em que os direitos alienáveis dos indivíduos à propriedade privada e à taxa de lucro se sobrepõem a toda outra concepção concebível de direitos inalienáveis".

5 Nesta linha, consultar também BRITO, Rodrigo Toscano de; ARAÚJO, Fábio José de Oliveira. Contratos, Superendividamento e a Proteção dos Consumidores na atividade econômica. Revista Direito e Desenvolvimento, João Pessoa, v. 5, n. 9, p. 165-204, jan/jun. 2014, p.173.

6 Não se desconsidera o contido no Decreto 7.397 de 2010 que institui a Estratégia Nacional de Educação Financeira - ENEF com a finalidade de promover a educação financeira e previdenciária e contribuir para o fortalecimento da cidadania, a eficiência e solidez do sistema financeiro nacional e a tomada de decisões conscientes por parte dos consumidores. No entanto, para fins do referido artigo, entende-se que o Estado deve se preocupar, para além da educação financeira, também com a efetividade de uma Política que apresente, no presente, a solução devida. 
é de fundamental importância, particularmente pela natureza do conflito e suas implicações de ordem financeira, pessoal, e social.

Nesse sentido, considerando que as recentes políticas públicas voltadas para o estímulo da prática da autocomposição não contemplam procedimentos especificamente voltados para o consumidor em situação de endividamento e superendividamento, cabe destacar projetos voltados para esta temática, do que se ocupa o item a seguir.

\section{A EXPECTATIVA DE REGULAMETAÇÃO DA CONCILIAÇÃO EM CASO DE SUPERENDIVIDAMENTO NO CÓDIGO DE DEFESA DO CONSUMIDOR}

O Poder Judiciário do Rio Grande do Sul (TJRS) desenvolve projeto pioneiro voltado para o tratamento do consumidor superendividado, por meio do Projeto de Tratamento do Superendividamento implantado em 2006 (TJRS, 2006). O Projeto propõe-se à conciliação global do consumidor em situação de superendividamento perante todos os seus credores, reabilitando-o economicamente e reeducando-o novamente para o consumo consciente. Mediante remessa de carta-convite aos credores declarados, por interesse da parte devedora, o procedimento é instaurado para a composição de dívidas civis.

O Projeto, portanto, está destinado ao uso do procedimento de conciliação quando reunidos devedor e todos os seus credores, a fim de construir um plano de pagamento das dívidas cobradas por todos os credores do consumidor, adequando os pagamentos à sua fonte de renda (LIMA, 2014, p.139-140). O plano pode prever parcelamento, dilação do prazo para pagamento, redução de encargos moratórios, redução de juros remuneratórios e até mesmo a prática ou abstenção de atos garantidores do adimplemento, como venda de algum bem ou impedimento para contração de novos empréstimos (LIMA, 2014, p.158).

Sob outro aspecto, o Projeto do TJRS prevê a organização de oficinas de orçamento familiar, de caráter interdisciplinar, envolvendo conhecimentos das áreas do direito, educação, informática, psicologia, economia, serviço social, tendo como público alvo os consumidores que recorreram ao tratamento do superendividamento bem como seus familiares e lideranças comunitárias (BRASIL, Ministério da Justiça, 2010, p.131).

É justamente essa conjunção de interesses que torna o procedimento eficaz, na medida em que compromete o consumidor a honrar o acordo com todos os seus credores, ao tempo em que lhe preserva com renda mínima necessária para a sua subsistência (LIMA, 2014, p.139140). Segundo Clarissa Costa de Lima, entrevistas realizadas com devedores que participaram do Projeto capitaneado pelo TJRS confirmam o efeito pedagógico e educativo dos planos de pagamento (2014, p.157).

Em 2012 o procedimento da conciliação das hipóteses de superendividamento integra e é regulado pelo art.1040-A da Consolidação Normativa Judicial do Tribunal gaúcho (TJRS, 2012), o que possibilita, em processos dessa natureza, a utilização de fase de conciliação prévia ao processo judicial a partir da instauração de concurso de credores, mediante remessa de carta-convite aos credores declarados, por interesse da parte devedora, para a composição de dívidas civis, ou seja, nos mesmos moldes do projeto institucional. A homologação de acordo em audiência designada para esta finalidade constitui título executivo judicial, independentemente da representação das partes por advogados.

Atualmente, boa parte dos procedimentos para o tratamento do superendividamento estão absorvidos pelos Centros Judiciais de Solução de Conflitos e de Cidadania - CEJUSCs, nas Comarcas no Estado onde os Centros estão organizados. De qualquer modo, na ausência dos CEJUSCs, qualquer magistrado está apto a adotar o procedimento de conciliação previsto para 
o tratamento do consumidor superendividado, eis que amparado e regulado pelo normativo do Tribunal.

O vanguardismo do projeto do TJRS deu ensejo, ainda, à proposta de alteração do Código de Defesa do Consumidor, através do Projeto de Lei do Senado no 283, que hoje se encontra incorporado ao Projeto de Lei no 3515 da Câmara dos Deputados. Segundo o texto normativo da proposta, pretende-se incluir a fase de conciliação nos procedimentos judiciais e extrajudiciais, através da qual o plano de pagamento será constituído entre devedor e credores. Atualmente, na tramitação da Câmara, o projeto aguarda criação de comissão especial.

Do referido projeto de lei, no aspecto principiológico, destaca-se de pronto a alteração prevista para o artigo $4^{\circ}$ do $C D C$, que inclui ações que fomentem a educação financeira e ambiental dos consumidores e a prevenção e tratamento do superendividamento como forma de evitar a exclusão social do consumidor. Também no art. $5^{\circ}$ do CDC, o projeto sugere a instituição de mecanismos de prevenção e tratamento extrajudicial e judicial do superendividamento e de proteção do consumidor pessoa natural, bem como núcleos de conciliação e mediação de conflitos oriundos de superendividamento. No art.6o, por sua vez, o projeto pretende garantir ao consumidor práticas de crédito responsável, de educação financeira e de prevenção e tratamento de situações de superendividamento, com vistas à preservação do preservado o mínimo existencial.

Sob o aspecto procedimental, ao introduzir capítulo especial destinado à conciliação nos casos de endividamento, o projeto prevê a inserção do art.104-A, disciplinando o procedimento a partir do requerimento do consumidor superendividado. Estão excluídas deste procedimento a repactuação das dívidas de caráter alimentar, as fiscais, as parafiscais, bem como as dívidas oriundas dos contratos de crédito com garantia real, dos financiamentos imobiliários e dos contratos de crédito rural.

Segundo a proposta de lei, a partir do requerimento do consumidor, o ritual segue para a realização de audiência conciliatória, presidida por juiz ou por conciliador credenciado no juízo, com a presença de todos os credores, na qual o consumidor deve apresentar proposta de plano de pagamento com prazo máximo de 5 (cinco) anos, preservados o mínimo existencial, bem como as garantias e as formas de pagamento originalmente pactuadas. $\mathrm{O}$ art.104- $\mathrm{C}$, também a ser inserido acaso o projeto seja aprovado, inclusive, reforça a possibilidade de realização de conciliação nos órgãos públicos integrantes do Sistema Nacional de Defesa do Consumidor, como fase conciliatória e preventiva do processo de repactuação de dívidas.

O projeto também prevê que, caso a conciliação em relação a quaisquer credores seja inexitosa, o juiz, a pedido do consumidor, instaurará processo por superendividamento para revisão e integração dos contratos e repactuação das dívidas remanescentes mediante plano judicial compulsório, procedendo à citação de todos os credores cujos créditos não tenham integrado o acordo porventura celebrado.

\section{CONSIDERAÇÕES FINAIS}

A autocomposição apresenta uma significativa perspectiva de remodelação do acesso à justiça, bem como pode trazer uma resposta mais adequada à natureza dos conflitos da contemporaneidade, então não experimentadas no momento em que o direito processual nasce como ciência para o tratamento de conflitos nos séculos passados.

No caso do consumidor endividado ou superendividado, é ainda mais evidente a necessidade de compatibilizar o ritual de tratamento do conflito com a sua natureza, mormente 
por se tratar de um problema social contemporâneo e implicar severas consequências sobre a qualidade de vida do cidadão e de sua família.

Não se pode mais tratar um conflito na contemporaneidade com os mesmos métodos utilizados dos séculos passados. Os procedimentos contenciosos previstos pelo novo Código de Processo Civil, além de não pacificarem o problema social, não possuem aptidão para, de forma célere e preventiva, tratar o superendividamento na medida da sua complexidade e ainda reeducar o consumidor para o consumo consciente.

Nessa perspectiva, a autocomposição mostra-se como mecanismo mais adequado para conflitos dessa natureza, na perspectiva do acesso à justiça, especialmente por se tratar de procedimento que de fato reabilita o consumidor para o consumo, ao tempo em que lhe garante o mínimo existencial para seguir no seu auto sustento e de sua família.

\section{REFERÊNCIAS}

ABBOUD, Georges; CAVALCANTI, Marcos de Araújo. Inconstitucionalidades do Incidente de Resolução de Demandas Repetitivas (IRDR) e os riscos ao sistema decisório. Revista de Processo, São Paulo, vol.240, p.221/242, fev.2015. Disponível em: < http://www.bvr.com.br/ abdpro/wp-content/uploads/2016/o3/Inconstitucionalidades-do-IRDR-e-riscos-ao-sistemadecisorio-.pdf $>$. Acesso em: 05 mar.2018.

ALCALÁ-ZAMORA Y CASTILLO, Niceto. Proceso, autocomposicion y autodefesa. México: Universidad Atónoma Nacional de México, 1991.

AMARAL, Guilherme Rizzo. Efetividade, segurança, massificação e a proposta de resolução de demandas repetitivas. Revista Magister de Direito Civil e Processual Civil, Porto Alegre, v.9, n.54, p.47-78, abr.2013.

BARONE, Francisco Marcelo; SADER, Emir. Acesso ao crédito no Brasil: evolução e perspectivas. Revista de Administração Pública, Rio de Janeiro, v. 42, n. 6, nov./dez. 2008. Disponível em <http://www.scielo.br/pdf/rap/v42n6/12.pdf>. Acesso em: 21Julho2o18.

BELLO, Enzo. Teoria dialética da cidadania: política e direito na atuação dos movimentos sociais urbanos de ocupação na cidade do Rio de Janeiro. 2011. Tese de Doutorado. Tese (Doutorado em Direito). Universidade do Estado do Rio de Janeiro.

BRASIL, Cadastro Nacional de Reclamações Fundamentadas. Disponível em: <http:// www.justica.gov.br/seus-direitos/consumidor/Anexos/cadastronacionalreclamacoes2012.pdf> Acesso em 22Julho2018.

Câmara dos Deputados. Projeto de Lei no 3515. Disponível em <http://www.camara. gov.br/proposicoesWeb/fichadetramitacao?idProposicao=2052490 $>$. Acesso em: 22Julho2018

Confederação Nacional do Comércio, Bens, Serviços e Turismo. Pesquisa de endividamento e inadimplência do consumidor. Disponível em <http://cnc.org.br/sites/default/ files/arquivos/analise_peic_-_junho_2018.pdf> Acesso em 22 Julho.2018 
Conselho Nacional de Justiça. Demandas repetitivas e a morosidade na justiça cível brasileira. Julho 2011. Disponível em: <http://www.cnj.jus.br/files/conteudo/ arquivo/2016/o3/f7bif72aod31cc1724647c9147c4b66b.pdf>, Acesso em 22Julho.2018

. Conselho Nacional de Justiça. 100 Maiores Litigantes. Disponível em: < http://www. cnj.jus.br/images/pesquisas-judiciarias/Publicacoes/10o_maiores_litigantes.pdf $>$, Acesso em o6 Maio.2018

, Conselho Nacional de Justiça. Relatório Justiça em Números 2017. Disponível em: $<$ http://www.cnj.jus.br/programas-e-acoes/pj-justica-em-numeros> Acesso em: 17 Set.2017.

Conselho Nacional de Justiça. Relatório Justiça em Números 2016. Disponível: em <http://www.cnj.jus.br/files/conteudo/arquivo/2016/10/b8f46be3dbbff344931a933579915488. pdf $>$ Acesso em: 17 Set.2017.

IBGE. Síntese dos Indicadores Sociais: uma análise das condições de vida da população brasileira. 2017, p.16. Disponível em: < https://biblioteca.ibge.gov.br/visualizacao/ livros/liv101459.pdf>. Acesso em: 16 Jun2018.

Ministério da Justiça. Caderno de Investigações Científicas - Volume 1, 2010. Prevenção e Tratamento do Superendividamento. Escola Nacional de Defesa do Consumidor. Disponível em <http://www.justica.gov.br/seus-direitos/consumidor/Anexos/ manual-tratamento-do-super\%2oendividamento.pdf> Acesso em: 21Julho2o18.

Planalto. Lei n. 13.105, de 17 de março de 2015. Institui o novo Código de Processo Civil. Disponível em: <http://www.planalto.gov.br/ccivil_03/_Ato2015-2018/2015/Lei/L13105. htm.>. Acesso em: 18Mar2015.

Ministério da Justiça. Secretaria Nacional do Consumidor. Relatório do Cadastro Nacional de Reclamações Fundamentadas 2o12. Disponível em: <http://www.justica. gov.br/seus-direitos/consumidor/Anexos/cadastronacionalreclamacoes2012.pdf> Acesso em 22Julho2018.

, Secretaria de Assuntos Estratégicos. Plataforma Vozes da Classe Média. Disponível em <http://www.sae.gov.br/site/wp-content/uploads/Cartilha-Vozes-Classe-Media.pdf>. Acesso em 26 Mar. 2014.

BRITO, Rodrigo Toscano de; ARAÚJO, Fábio José de Oliveira. Contratos, Superendividamento e a Proteção dos Consumidores na atividade econômica. Revista Direito e Desenvolvimento, João Pessoa, v. 5, n. 9, p. 165-204, jan/jun. 2014, p.173.

BUCAR, Daniel. Superendividamento - reabilitação patrimonial da pessoa humana. São Paulo: Saraiva, 2017.

CALMON, Petronio. Fundamentos da Conciliação e da Mediação. Brasília: Gazeta Jurídica, 2015 . 
CALAMANDREI, Piero. Proceso y Democracia. (tradução para o espanhol de Hector Fix Zamudio) Buenos Aires: Editora EJEA, 1960.

CARNELUTTI, Francesco. Instituciones del Proceso Civil. Volume I. Buenos Aires: EJEA, 1959.

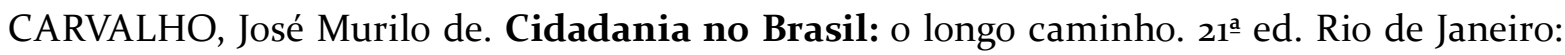
Civilização Brasileira, 2016.

CASTANHEIRA NEVES, Antonio. Questão fato e Questão de direito - o problema metodológico da juridicidade. Coimbra: Coimbra, 1967.

CASTELLS, Manoel. A Sociedade em Rede. Volume I. 18ª ed.rev. ampl. São Paulo: Paz e Terra, 2017.

CHANG, Ha-Joo. 23 Coisas que não nos contaram sobre o capitalismo. São Paulo: Cultrix, 2013.

CHASE, Oscar G. Direito Cultura e Ritual: Sistemas de Resolução de conflitos no contexto da cultura comparada. $1^{a}$ edição. Tradução de Sérgio Arenhart, Gustavo Osna. São Paulo: 2014.

CHEVALLIER, Jacques. O Estado pós-moderno. Belo-Horizonte: Fórum: 2009.

CHIOVEDA, Giuseppe. Instituições de direito processual civil. Tradução Paolo Capitaneo. Campinas: Bookseller, 1998, Vol.2.

GADAMER, Hans Georg. Verdade e Método I. Petrópolis: Vozes, 2004.

GARCIA-PELAYO, Manuel. Las transformaciones del estado conteporaneo. Madrid: Alianza, 1982.

HOFMEISTER. Maria Alice Costa. Superendividamento e violência contra a mulher. Direito \& Justiça, Porto Alegre, v. 41, n. 2, p. 214-224, jul.-dez. 2015. Disponível em <http:// revistaseletronicas.pucrs.br/ojs/index.php/fadir/article/view/21435/13337> Acesso em 22Julho2018

LIMA, Clarissa Costa de. O tratamento do superendividamento e o direito de recomeçar dos consumidores. São Paulo: Revista dos Tribunais, 2014.

LIPOVETSKY, Gilles. A felicidade paradoxal: ensaio sobre a sociedade de hiperconsumo. São Paulo: Companhia das Letras, 2007.

MARINONI, Luiz Guilherme. Precedentes Obrigatórios. São Paulo: Revista dos Tribunais, 2011.

MIRAGEM, Bruno; LIMA, Clarissa Costa de. Patrimônio, contrato e proteção constitucional da família: estudo sobre as repercussões do superendividamento sobre as relações familiares. Revista de Direito do Consumidor. São Paulo, n..91, p.85-116, janeiro-fevereiro de 2014. 
MITIDIERO, Daniel. Precedentes - da persuasão à vinculação. São Paulo: Revistas dos Tribunais, 2017.

MORA, Mônica. A evolução do crédito no Brasil entre 2003 e 2010. Disponível em <http:// repositorio.ipea.gov.br/bitstream/11058/3537/1/td2022.pdf> Acesso em 22Julho2018.

NERY, Rosa Maria de Andrade; NERY JUNIOR, Nelson. Código de processo civil comentado. In: Código de processo civil comentado. Revista dos Tribunais, 2016.

NERY JUNIOR, Nelson. ABBOUD, Georges. Stare Decisis vs Direito Jurisprudencial. In: FREIRE, Alexandre, et. alii. Novas Tendências do Processo Civil: Estudos Sobre o Projeto de Novo Código de Processo Civil. Bahia: Editora JusPodivm, 2013, p. 483-512.

NUNES, Dierle; VIANA, Aurélio. Precedentes - a mutação no ônus argumentativo. Rio de Janeiro: Forense, 2018.

RIO GRANDE DO SUL. TJRS. Projeto de Tratamento do Superendividamento. Disponível em <https://www.tjrs.jus.br/site/processos/conciliacao/superendividamento.html > Acesso em 22Julho2018.

. TJRS. Consolidação Normativa Judicial. Disponível em <https://www.tjrs.jus.br/ export/legislacao/estadual/doc/CNJCGJ_Outubro_2012_Prov_18_2012_VC_.pdf> Acesso em: 22Julho2018.

ROSENBERG, Marsall B. Comunicaçãonão-violenta:técnicas para aprimorar relacionamentos pessoais e profissionais. São Paulo: Ágora, 2006 p.42

ROTH, André-Noel. O Direito em crise: fim do Estado Moderno. In: FARIA, José Eduardo. Direito e Globalização Econômica: implicações e perspectivas. São Paulo: Malheiros, 1996.

SANTOS, Karinne Emanoela Goettems dos. Processo Civil e Litigiosidade. Rio de Janeiro: Lumen Juris, 2016.

SILVA, Ovídio A. Baptista da. Jurisdição e Execução na tradição romano-canônica. São Paulo: Editora Revista dos Tribunais, 1997.

SOUZA SANTOS, Boaventura de. Pela mão de Alice. São Paulo: Cortez Editora, 2008.

STRECK, Lenio Luiz. Verdade e Consenso. Constituição, Hermenêutica e Teorias Discursivas. Da possibilidade à necessidade de respostas corretas em Direito. Rio de Janeiro: 2009.

STRECK, Lenio Luiz; ALVIM, Eduardo Arruda; LEITE, George Salomão. Hermenêutica e Jurisprudência no Novo Código de Processo Civil: Coerência e Integridade. São Paulo: Saraiva, 2016.

TOURAINE, Alain. Um novo paradigma: para compreender o mundo hoje. Petrópolis: Vozes, 2007. 
WARAT, Luis Alberto (ORG.). Em nome do acordo. A mediação no direito. 2ª edição. Buenos Aires: Almed, 1999.

WEBER, Max. A ética protestante e o espírito do capitalismo. São Paulo: Companhia das Letras: 2004. 